\title{
SETORES-CHAVE E ÍNDICES DE LIGAÇÕES NO MUNICÍPIO DE LONDRINA-PARANÁ
}

\author{
Renato Rugene de Carvalho* \\ Umberto Antonio Sesso Filho \\ Lorena Regina Oliveira \\ Willian Ruivo \\ Paulo Rogério Alves Brene
}

\begin{abstract}
Resumo: Este artigo tem como objetivo estimar o sistema inter-regional de insumo-produto Londrina-Paraná-Restante do Brasil para o ano de 2013, tornando possível a identificação de setores-chave para nortear políticas de desenvolvimento do município que proporcionem o maior retorno em termos de desenvolvimento econômico e social. Os resultados mostram que os setores com maior capacidade de geração de empregos locais são 17-Saúde; 16-Educação; 18Artes, cultura e recreação; 19-Outras atividades de serviços; e 14-Atividades administrativas e serviços complementares. As atividades econômicas de Londrina com maiores valores para o multiplicador de produção são 3-Indústria de transformação; 8-Transporte; 6-Construção; 9-Alojamento e alimentação; e 13-Informação e comunicação. Os setores-chave para a geração de rendimento formal em Londrina foram identificados como 16-Educação; 17-Saúde; 15Administração pública; 13-Atividades profissionais, científicas e técnicas; 18Artes, cultura, esporte e recreação. As 3-Indústrias de transformação; 8Transporte; e 10-Informação e comunicação; foram identificadas como importantes com valores maiores de índices de ligações intersetoriais.
\end{abstract}

Palavras-chave: insumo-produto, Londrina, Economia regional.

\begin{abstract}
This articleaims to estimate the inter-regional system of input-output Londrina Parana-Remainder of Brazil for the year 2013, making it possible to identify key sectors to guide municipal development policies that provide the greatest return in terms economic and social development. The results show that the sectors with greater capacity for local employment generation are 17 health; 16 Education; 18 Arts, culture and recreation; 19 Other service activities; and 14 administrative activities and complementary services. The economic activities of Londrina with higher values for the production multiplier is 3-Manufacturing; 8Transportation; 6-Construction; 9 Accommodation and food; and 13 Information and communication. The key sectors for generating formal income in Londrina were identified as 16-Education; 17-Health; 15 Public Administration; professional, scientific and technical activities 13; 18 Arts, culture, sport and recreation. The 3-Manufacturing industry; 8-Transportation; and 10Information and communication; They were identified as important with higher values of intersectoral links indexes.
\end{abstract}

* Universidade Estadual de Londrina 
Keywords: input-output, Londrina, regional economics.

J EL: C67; O20; R15.

1. Introdução

As matrizes de insumo-produto inter-regionais podem ser estimadas ou construídas, os sistemas construídos demandam considerável volume de dados e tempo de trabalho enquanto as matrizes estimadas necessitam de uma base de dados menor. As matrizes de insumo-produto inter-regionais permitem uma análise detalhada do sistema econômico, este dividido em duas ou mais regiões e seus fluxos de bens e serviços. A estimação ou construção de matrizes regionais e inter-regionais de insumo-produto torna possível a determinação de setoreschave para o desenvolvimento econômico e social das regiões analisadas.

A estimação do sistema inter-regional de Londrina-Restante do Paraná-Restante do Brasil possibilita analisar em detalhes a estrutura produtiva das regiões e identificar os setores-chave para a geração de emprego, produção e renda e relações intersetoriais do município. Além disso, os fluxos de bens e serviços entre as regiões serão analisados com o intuito de avaliar a interdependência econômica entre elas. O ano de referência para estimação 2013 foi escolhido pela disponibilidade de bases de dados mais recentes em junho de 2016.

O objetivo geral do estudo foi estimar sistemas inter-regionais de insumoproduto municipal de Londrina, estado e restante da economia para realizar análises estruturais e identificar setores-chave para o desenvolvimento econômico e social do município. Especificamente, pretende-se:

a) Estimar o sistema inter-regional de insumo-produto Londrina-Restante do Paraná-Restante do Brasil;

b) Calcular indicadores econômicos baseados na ferramenta insumo-produto e seus valores de transbordamento para identificar setores-chave para o desenvolvimento econômico e social.

O texto está dividido em quatro seções incluindo a introdução. Na segunda seção, a justificativa do projeto de pesquisa mostra a importância da estimação e construção da matriz de insumo-produto para análise da estrutura da economia regional com enfoque sobre o estado do Paraná e seus municípios. A terceira seção trata do referencial teórico utilizado na análise quantitativa do estudo e estimativa da matriz insumo-produto inter-regional e seus métodos de análise. A Quarta seção apresenta os resultados previstos para o projeto. A seguir serão analisadas as pesquisas recentes sobre matrizes de insumo-produto estimadas e construídas para regiões do Brasil (grandes regiões, estados e municípios).

\section{Matrizes de insumo-produto de municípios do estado do Paraná}

Issa et al (2015) realizaram uma análise comparativa das cidades de Arapongas/ PR e São Bento do Sul/ SC, duas cidades que são conhecidas por sua 
tradição no setor de madeira e mobiliário. Eles calcularam indicadores econômicos baseados na matriz de insumo-produto municipais e estimaram a importância do setor de madeira e móveis para cada município.

Caravieri et al (2014) avaliaram a contribuição do índice de RasmussenHirschman para a análise de Arranjos Produtivos Locais (APL) em conjunto com outros métodos. Como objeto de estudo, são utilizados os municípios de Arapongas/PR e São Bento do Sul/SC, notadamente reconhecidos no setor de madeira e mobiliário. O tema se justifica devido a sua importância e a falta de consenso dos métodos e conceitos. Os autores observaram queas diferenças entre os métodos de identificação que apresentam de um a sete APLS nos municípios analisados. Já, com base no índice Rasmussen-Hirschman, no caso específico do setor de madeira e mobiliário, este não se caracterizou como setor-chave em ambas as localidades. Em Arapongas os valores dos índices de ligação intersetoriais foram 1,10 (trás) e 0,88 (frente) e em São Bento do Sul foram 1,07 (trás) e 0,85 (frente). Analisando apenas os indicadores para trás, é possível observar que o setor é importante consumidor de insumos nos municípios, contudo não seria o mais importante ficando em $4^{\underline{a}}$ posição em Arapongas e $6^{\underline{a}}$ em São Bento do Sul.

Tarocco Filho et al (2014) analisaram a importância econômica da Universidade Estadual de Londrina e seus impactos locais e inter-regionais no ano de 2006 com relação a emprego e renda. Através da análise de insumo-produto, foram calculados os multiplicadores emprego e remunerações, geração de emprego e renda e os índices de ligação para trás e para frente. Através dos resultados verificou que a Educação Pública emprega 6,19\% do pessoal ocupado e é responsável por 12,27\% das remunerações geradas no município. A Educação Pública se destacou na geração de emprego em Londrina, que junto com os setores de Educação Mercantil e Serviços (13), foi o quarto maior indicador, ficando atrás dos setores: Administração Pública, Comércio e Indústrias Diversas e Mobiliários. Verificou-se que o valor do multiplicador de emprego é de 1,25 e sua capacidade de gerar remunerações por efeito direto no município é a terceira maior com $\mathrm{R} \$ 368.153$ milhões.

Fernandes et al (2014) desenvolveram pesquisa com objetivo de estimar e analisar o nível de interações sinergéticas através da matriz insumo-produto municipal e avaliar suas contribuições para diferentes metodologias de Arranjos Produtivos Locais (APL's). Como objetos de estudo foram escolhidos os municípios deArapongas (PR) e São Bento do Sul (SC) por sedestacarem no setor moveleiro.

Brene, Sesso Filho e Dalla Costa (2014) desenvolveram pesquisa com o objetivo de realizar uma análise de viabilidade do uso de indicadores econômicos provenientes de matrizes insumo-produto estimadas, sendo estas obtidas a partir Relação Anual de Informações Sociais (RAIS). Os resultados mostraram que os valores calculados podem ser utilizados para analisar o comportamento econômico local com o mínimo de custo financeiro, técnico e temporal. A metodologia pode ser utilizada para analisar a estrutura econômica dos Estados, Microrregiões ou Municípios principalmente quando os dados são escassos e 
existe uma importante demanda por ferramentas práticas para orientar políticas públicas locais.

Brene et al (2014) estimaram a matriz insumo-produto do município de Curitiba/Pr para o ano de 2006. Os resultados mostraram que os setores relacionados com as atividades de serviços e comércio se destacam nos multiplicadores simples do tipo I. No caso das atividades industriais, destaca-se o setor (7) Indústria Química, Farmacêutica e de Refino de Combustível apontado como setor-chave tanto pelo índice de Rasmussen-Hirschman, quanto pelo Índice Puro Normalizado. São apontados pelos dois métodos também os setores (15) Comunicação e (16) Intermediação financeira e seguros. Em relação ao campo de influência quatro setores se destacaram, sendo eles: (3) Fabricação de Alimentos e Bebidas; (5) Fabricação de Produtos de Madeira e Diversos; (11) S.I.U.P; e (16) Intermediação financeira e seguros.

A análise dos estudos baseados em matrizes de insumo-produto inter-regionais mostra que a estimação/construção da matriz torna possível a realização de diversos estudos analisando variáveis como produção, emprego e renda, ligações intersetoriais, além de desenvolver análises setoriais dos fluxos de bens e serviços entre as regiões e determinar o nível de interações sinérgicas e interdependência entre estas. A revisão de literatura mostra que existe limitado número de estudos sobre matrizes de insumo-produto municipais, considerando a construção e estimativa de sistemas estaduais e para países.

\section{Fundamentação teórico-metodológica}

O capítulo apresenta o cálculo de indicadores econômicos baseados na ferramenta insumo-produto e o método de estimação de matrizes. No decorrer do projeto, poderão ser calculados outros indicadores e análises adicionais poderão ser realizadas.

\subsection{0 sistema inter-regional de insumo produto}

A matriz de insumo-produto do Brasil para o ano de 2013 será obtida a partir da metodologia proposta por Guilhoto e Sesso Filho (2005). A estimativa da matriz do Paraná e Municípios será realizada a partir dos dados do Ministério do Trabalho e Contas Regionais do IBGE (2016) com a metodologia proposta em Brene et al (2014). Métodos de estimação adicionais serão baseados em Guilhoto e Sesso Filho (2005b). A base de dados adicional se refere ao Instituto Paranaense de Desenvolvimento Econômico e Social (IPARDES), que pode disponibilizar dados da microrregião, estaduais e municipais para o desenvolvimento da pesquisa.

O modelo inter-regional de insumo-produto, também chamado de "modelo Isard", devido à aplicação de Isard (1951), requer uma grande massa de dados, reais ou estimados, principalmente quanto às informações sobre fluxos intersetoriais e inter-regionais. O Quadro 1 apresenta de uma forma esquemática as relações dentro de um sistema de insumo-produto inter-regional com duas 
regiões. Complementando o sistema regional, no sistema inter-regional há uma troca de relações entre as regiões, exportações e importações, que são expressas por meio do fluxo de bens que se destinam tanto ao consumo intermediário como à demanda final.

Figura 1. Relações de Insumo-Produto num sistema inter-regional com duas regiões

\begin{tabular}{|c|c|c|c|c|c|}
\hline & Setores - Região L & Setores - Região M & $\mathrm{L}$ & $\bar{M}$ & \\
\hline $\begin{array}{c}\text { Setore } \\
\text { S } \\
\text { Regiã } \\
\text { o } \\
\text { L }\end{array}$ & $\begin{array}{c}\text { Insumos } \\
\text { Intermediários } \\
\text { LL }\end{array}$ & $\begin{array}{c}\text { Insumos } \\
\text { Intermediários } \\
\text { LM }\end{array}$ & DF LL & $\begin{array}{l}\text { DF } \\
\text { LM }\end{array}$ & $\begin{array}{l}\text { Produç } \\
\text { ão } \\
\text { Total } \\
\text { L }\end{array}$ \\
\hline \multirow[t]{5}{*}{$\begin{array}{c}\text { Setore } \\
\text { S } \\
\text { Regiã } \\
\text { O } \\
\text { M } \\
\end{array}$} & $\begin{array}{c}\text { Insumos } \\
\text { Intermediários } \\
\text { ML }\end{array}$ & $\begin{array}{c}\text { Insumos } \\
\text { Intermediários } \\
\text { MM }\end{array}$ & $\begin{array}{l}\text { DF } \\
\text { ML }\end{array}$ & $\begin{array}{l}\mathrm{DF} \\
\mathrm{MM}\end{array}$ & $\begin{array}{c}\text { Produç } \\
\text { ão } \\
\text { Total } \\
\text { M }\end{array}$ \\
\hline & $\begin{array}{c}\text { Importação do } \\
\text { Restante do Mundo } \\
\text { (M) }\end{array}$ & $\begin{array}{c}\text { Importação do } \\
\text { Restante do Mundo } \\
\text { (M) }\end{array}$ & M & M & M \\
\hline & $\begin{array}{l}\text { Impostos Indiretos } \\
\text { Líquidos (IIL) }\end{array}$ & $\begin{array}{l}\text { Impostos Indiretos } \\
\text { Líquidos (IIL) }\end{array}$ & IIL & IIL & IIL \\
\hline & Valor Adicionado & Valor Adicionado & & & \\
\hline & $\begin{array}{l}\text { Produção Total } \\
\text { Região L }\end{array}$ & $\begin{array}{l}\text { Produção Total } \\
\text { Região M }\end{array}$ & & & \\
\hline
\end{tabular}

Fonte: Adaptado de Moretto (2000)

De forma sintética, pode-se apresentar o modelo, a partir do exemplo hipotético dos fluxos intersetoriais e inter-regionais de bens para as regiões L e M, com 2 setores, como se segue:

$$
\begin{aligned}
& Z_{i j}^{L L} \text { - fluxo monetário do setor i para o setorj da região } \mathrm{L}, \\
& Z_{i j}^{M L} \text { - fluxo monetário do setor i da região } \mathrm{M} \text {, para o setor j da região L. }
\end{aligned}
$$

Na forma de matriz, esses fluxos seriam representados por:

$$
Z=\left[\begin{array}{ll}
Z^{L L} & Z^{L M} \\
Z^{M L} & Z^{M M}
\end{array}\right]
$$

em que

$Z^{L L}$ e $Z^{M M}$, representam matrizes dos fluxos monetários intra-regionais, e 
$Z^{L M}$ e $Z^{M L}$, representam matrizes dos fluxos monetários inter-regionais.

Considerando a equação de Leontief (1951 e 1986)

$$
X_{i}=z_{i 1}+z_{i 2}+\ldots+z_{i i}+\ldots+z_{i n}+Y_{i}
$$

em que, $X_{i}$ indica o total da produção do setor i, $z_{\text {in }}$ o fluxo monetário do setor i para o setor $\mathrm{n}$ e $Y_{\mathrm{i}}$ a demanda final por produtos do setor i, é possível aplicá-la conforme,

$$
X_{1}^{L}=z_{11}^{L L}+z_{12}^{L L}+\ldots+z_{11}^{L M}+z_{12}^{L M}+\ldots+Y_{1}^{L}
$$

em que $X_{1}^{L}$ é o total do bem 1 produzido na região L.

Considerando os coeficientes de insumo regional para L e M, obtêm-se os coeficientes intra-regionais:

$$
a_{i j}^{L L}=\frac{z_{i j}^{L L}}{X_{j}^{L}} \quad \Rightarrow \quad z_{i j}^{L L}=a_{i j}^{L L} \cdot X_{j}^{L}
$$

em que, pode-se definir os $a_{i j}^{L L}$ como coeficientes técnicos de produção que representam quanto o setor $j$ da região L compra do setor i da região L e

$$
a_{i j}^{M M}=\frac{z_{i j}^{M M}}{X_{j}^{M}} \quad \Rightarrow \quad z_{i j}^{M M}=a_{i j}^{M M} \cdot X_{j}^{M}
$$

em que, pode-se definir os $a_{i j}^{M M}$ como coeficientes técnicos de produção, que representam a quantidade que o setor $\mathrm{j}$ da região $\mathrm{M}$ compra do setor i da região M.

E, por último, os coeficientes inter-regionais:

$$
a_{i j}^{M L}=\frac{z_{i j}^{M L}}{X_{j}^{L}} \quad \Rightarrow \quad z_{i j}^{M L}=a_{i j}^{M L .} \cdot X_{j}^{L}
$$

podendo-sedefinir os $a_{i j}^{M L}$. como coeficientes técnicos de produção que representam quanto o setor j da região L compra do setor i da região Me

$$
a_{i j}^{L M}=\frac{z_{i j}^{L M}}{X_{j}^{M}} \quad \Rightarrow \quad z_{i j}^{L M}=a_{i j}^{L M} \cdot X_{j}^{L}
$$


em que os $a_{i j}^{L M}$ correspondem aos coeficientes técnicos de produção que representam a quantidade que o setor $\mathrm{j}$ da região $\mathrm{M}$ compra do setor i da região L.

Estes coeficientes podem ser substituídos em (3), obtendo:

$$
X_{1}^{L}=a_{11}^{L L} X_{1}^{L}+a_{12}^{L L} X_{2}^{L}+a_{11}^{L M} X_{1}^{M}+a_{12}^{L M} X_{2}^{M}+Y_{1}^{L}
$$

As produções para os demais setores são obtidas de forma similar.

Isolando, $Y_{1}^{L}$ e colocando em evidência $X_{1}^{L}$, tem-se:

$$
\left(1-a_{11}^{L L}\right) X_{1}^{L}-a_{12}^{L L} X_{2}^{L}-a_{11}^{L M} X_{1}^{M}-a_{12}^{L M} X_{2}^{M}=Y_{1}^{L}
$$

As demais demandas finais podem ser obtidas similarmente. Portanto, de acordo com $A^{L L}=Z^{L L}\left(\hat{X}^{L}\right)^{-1}$, obtém-se a matriz $A^{L L}$, para os 2 setores, em que $A^{L L}$ representa a matriz de coeficientes técnicos intra-regionais de produção. Saliente-se que esta mesma formulação valeria para $A^{L M}, A^{M M}, A^{M L}$.

Definem-se agora as seguintes matrizes:

$$
\begin{gathered}
A=\left[\begin{array}{ccc}
A^{L L} & \vdots & A^{L M} \\
\cdots & \cdots & \cdots \\
A^{M L} & \vdots & A^{M M}
\end{array}\right] \\
X=\left[\begin{array}{c}
X^{L} \\
\cdots \\
X^{M}
\end{array}\right] \\
Y=\left[\begin{array}{c}
Y^{L} \\
\cdots \\
Y^{M}
\end{array}\right]
\end{gathered}
$$

O sistema inter-regional completo de insumo-produto é representado por:

$$
(I-A) X=Y
$$

e as matrizes podem ser dispostas da seguinte forma:

$$
\left\{\left[\begin{array}{ccc}
I & \vdots & 0 \\
\hdashline & \because & \cdots \\
0 & \vdots & I
\end{array}\right]-\left[\begin{array}{ccc}
A^{L L} & \vdots & A^{L M} \\
\dddot{M} & \because & \dddot{M} M
\end{array}\right]\right\}\left[\begin{array}{c}
X^{L} \\
\cdots \\
X^{M}
\end{array}\right]=\left[\begin{array}{c}
Y^{L} \\
\cdots \\
Y^{M}
\end{array}\right]
$$

Efetuando estas operações, obtêm-se os modelos básicos necessários à análise inter-regional proposta por Isard, resultando no sistema de Leontief interregional da forma: 


$$
X=(I-A)^{-1} Y
$$

A matriz inversa de Leontief é dada por

$$
L=(I-A)^{-1}
$$

e seus elementos são $b_{\mathrm{ij}}$.

\subsection{Topografia econômica}

Na maior parte dos estudos que utilizam a análise de insumo-produto, o volume de resultados é muito grande e normalmente resumido em longas tabelas. A topografia econômica busca utilizar os resultados dos cálculos a partir da matriz de insumo-produto para elaborar gráficos que facilitam a visualização dos valores. Portanto, a distribuição dos valores dentro da matriz de variáveis como geradores de produção, emprego, renda e seus efeitos diretos eindiretos pode ser visualizada por meio de gráficos de superfície. A análise de topografia econômica torna possível apresentar conclusões gerais sobre os resultados antes de analisar em detalhes os valores (Guilhoto et al., 2002).

\subsection{Geradores e multiplicadores}

A partir dos coeficientes diretos e da matriz inversa de Leontief é possível estimar para cada setor da economia o quanto é gerado direta e indiretamente de emprego, importações, impostos, salários, valor adicionado ou outra variável em análise para cada unidade monetária produzida para a demanda final (Miller e Blair, 2009). Ou seja:

$$
G V_{j}=\sum_{i=1}^{n} b_{i j} v_{i}
$$

Onde:

$G V_{j}$ é o impacto total, direto e indireto, sobre a variável em questão;

$b_{i j}$ é o ij-ésimo elemento da matriz inversa de Leontief e

$v_{i}$ é o coeficiente direto da variável em questão.

A divisão dos geradores pelo respectivo coeficiente direto gera os multiplicadores, que indicam quanto é gerado, direta e indiretamente, de emprego, importações, impostos, ou qualquer outra variável para cada unidade diretamente gerada desses itens. Por exemplo, o multiplicador de empregos indica a quantidade de 
empregos criados, direta e indiretamente, para cada emprego direto criado. $\mathrm{O}$ multiplicador do i-ésimo setor seria dado então por:

$$
M V_{i}=\frac{G V_{i}}{V_{i}}
$$

onde $M V_{i}$ representaria o multiplicador da variável em questão e as outras variáveis são definidas conforme feito anteriormente.

Por sua vez, o multiplicador de produção que indica o quanto se produz para cada unidade monetária gasta no consumo final é definido como:

$$
M P_{j}=\sum_{i=1}^{n} b_{i j}
$$

Onde $M P_{j}$ é o multiplicador de produção do j-ésimo setor e as outras variáveis são definidas segundo o expresso anteriormente.

Quando o efeito de multiplicação se restringe somente à demanda de insumos intermediários, estes multiplicadores são chamados de multiplicadores do tipo I. Porém, quando a demanda das famílias é endogenizada no sistema, levando-se em consideração o efeito induzido, estes multiplicadores recebem a denominação de multiplicadores do tipo II.

\subsection{Método do quociente locacional}

O método do quociente locacional constitui uma técnica bastante empregada em Economia Regional, quando se deseja obter uma primeira aproximação do valor de determinadas variáveis para uma região qualquer, a partir do valor das mesmas variáveis obtidas por dados censitários em nível nacional. Segundo Souza (1997), a utilização dessa técnica supõe que a economia da região j mantém a mesma estrutura da economia nacional em relação à indústria i.

Assim, o quociente locacional simples para o setor i na região $\mathrm{R}$, conforme Miller e Blair (2009), é definido como:

$$
L Q_{i}^{R}=\left[\frac{X_{i}^{R} / X^{R}}{X_{i}^{N} / X^{N}}\right]
$$

em que:

$X_{i}^{R}$ e $X^{R}$ denotam, respectivamente, os valores da produção do setor i e da produção total na região $\mathrm{R}$; 
$X_{i}^{N}$ e $X^{N}$ denotam, respectivamente, os valores da produção do setor i e da produção total nacional.

Quando os dados de produção de uma indústria, em uma dada região, não estão disponíveis, pode-se utilizar outras medidas ou variáveis por setor, dentre as quais se destacam o emprego, a renda pessoal recebida, o valor adicionado, a demanda final, etc. (Miller e Blair, 2009).

O presente método consiste em comparar a proporção do produto total da região $\mathrm{R}$ que é devida ao setor i com a proporção do produto total nacional advindo do setor i em nível nacional. O quocientelocacional simples pode ser visto como uma medida da habilidade da indústria regional i para atender à demanda de outras indústrias e à demanda final da região. Se o valor do quociente for menor do que um, a indústria i é menos concentrada na região do que em nível nacional. Se for maior do que um, a indústria i é mais concentrada na região do que em nível nacional. Assim, para a linha i de uma tabela regional estimada, tem-se:

$$
a_{i j}^{R R}= \begin{cases}a_{i j}^{N}\left(L Q_{i}^{R}\right) & \text { se } L Q_{i}^{R}<1 \\ a_{i j}^{N} & \text { se } L Q_{i}^{R} \geq 1\end{cases}
$$

em que:

$a_{i j}^{R R}$ é o coeficiente de insumo regional;

$a_{i j}^{N}$ é o coeficiente técnico nacional;

A metodologia de estimação utilizando o quociente locacional para estados e municípios está descrita em Brene et al (2014b).

\subsection{5 Campo de influência}

Apesar de os índices de Rasmussen/Hirschman avaliarem a importância de um dado setor em termos dos seus impactos no sistema como um todo, é difícil visualizar os principais elos dentro da economia, ou seja, quais seriam os coeficientes que se alterados teriam um maior impacto no sistema econômico. O conceito de campo de influência (veja Sonis e Hewings, 1989, 1995) descreve como se distribuem as mudanças dos coeficientes diretos no sistema econômico, permitindo, desta forma, determinar quais as relações entre os setores que seriam mais importantes dentro do processo produtivo. Como poderá ser observada posteriormente, a noção de campo de influência não está dissociada da dos índices de ligações, sendo uma análise complementar a esta na medida em que os 
principais elos de ligação dentro da economia estariam associados aos setores que apresentam os maiores índices de ligações, tanto para frente, como para trás.

O desenvolvimento do conceito de campo de influência se beneficiou das idéias de Sherman e Morrison (1949, 1950), Evans (1954), Park (1974), Simonovits (1975), e Bullard e Sebald (1977, 1988), sendo que uma descrição mais detalhada pode ser encontrada em Sonis e Hewings $(1989,1995)$. Conforme exposto anteriormente, $A=\left|a_{i j}\right|$ representa a matriz de coeficientes diretos, e defininemse, a partir de então, $E=\left|\varepsilon_{i j}\right|$ como sendo a matriz de variações incrementais nos coeficientes diretos de insumo. As correspondentes matrizes inversas de Leontief são dadas por $B=[I-A]^{-1}=\left|b_{i j}\right|$ e por $B(\varepsilon)=[I-A-\varepsilon]^{-1}=\left|b_{i j}(\varepsilon)\right|$. Seguindo Sonis e Hewings (1989, 1995), caso a variação seja pequena e só ocorra num coeficiente direto, isto é:

$$
\varepsilon_{i j}=\left\{\begin{array}{cc}
\varepsilon & i=i_{1}, j=j_{1} \\
0 & i \neq i_{1}, \text { ou }, j \neq j_{1}
\end{array}\right.
$$

tem-se que o campo de influência desta variação pode ser aproximado pela expressão:

$$
F\left(\varepsilon_{i j}\right)=\frac{\left\lfloor B\left(\varepsilon_{i j}\right)-B\right\rfloor}{\varepsilon_{i j}}
$$

em que $F\left(\varepsilon_{i j}\right)$ é uma matriz (nxn) do campo de influência do coeficiente ${ }^{a_{i j}}$.

Visando determinar quais seriam os coeficientes que possuiriam os maiores campos de influência, é necessário associar-se a cada matriz $F\left(\varepsilon_{i j}\right)$ um valor que seria dado por:

$$
S_{i j}=\sum_{k=1}^{n} \sum_{l=1}^{n}\left[f_{k l}\left(\varepsilon_{i j}\right)\right]^{2}
$$

em que $S_{i j}$ é o valor associado à matriz $F\left(\varepsilon_{i j}\right)$. Portanto, os coeficientes diretos que possuírem os maiores valores de ${ }^{S_{i j}}$ serão aqueles com os maiores campos de influência dentro da economia.

Sonis e Hewings (1995) apresentam um detalhamento maior do que o aqui exposto, inclusive considerando-se os casos em que mudanças acontecem não apenas em um único coeficiente, mas no total de uma linha ou de uma coluna, ou mesmo na matriz como um todo. O principal problema dos métodos estudados 
até o momento éque, apesar de eles analisarem a importância do setor em termos dos impactos globais, é difícil visualizar o grau com que estes impactos refletem a importância de um ou dois coeficientes (ou fluxos principais) dentro do setor e a natureza dos impactos fora deste dele; por exemplo, se o impacto é concentrado em um ou dois setores, ou é mais amplamente difundido para o resto da economia.

\section{Resultados e discussão}

Antes de iniciar a análise dos resultados é importante destacar que a agregação utilizada, 19 setores, permite juntar segmentos cuja participação isolada em empregos e salários são relativamente pequenos para a economia como um todo. Assim, dentro da similaridade baseada na classificação do CNAE, os setores foram incorporados, aumentando a participação relativa no produto global. Ao mesmo tempo se ressalta que a análise privilegiará as cadeias com maior potencial e impacto na economia local.

Ainda sobre a agregação, o Setor de Serviços, que é composto pelos setores 7 ao 19 , ocupa mais de $70 \%$ dos empregos formais da cidade. Neste grupo, chama a atenção 7-Comércio; 14-Atividades administrativas; 16-Educaçao; e 17-Saúde, com mais de $48 \%$ dos empregos formais. São setores que por característica possuem alta intensidade em mão de obra e apresentam multiplicadores e geradores de emprego maiores. Por isso sua importância aumenta dentro de uma estratégia de emprego e renda tomada pelo poder público.

Outra observação relevante diz respeito à opção pelo ano escolhido, 2013. Ou seja, apenas um ano impede a análise sobre uma evolução dos indicadores. O motivo do ano, conforme já dito, é a disponibilidade de dados. Sobre a evolução no tempo, considerou-se que mudanças estruturais na econômica demandam tempo para se materializarem. Por outro lado, nada impede que os indicadores aqui apresentados possam ser objetos de estudos futuros com objetivo de confrontar uma variação estrutural do sistema e se houvemudanças relativas na distribuição das atividades econômicas. Para isso, é preciso ter em conta que os multiplicadores de emprego e rendimento podem ser comparados ao longo do tempo, já que não possuem unidade monetária. Mas os geradores devem considerar os efeitos da inflação, pois são números que contabilizam variação monetária, quer seja de um milhão de reais da demanda final.

Posto a questão da agregação e escolha do ano, é pertinente também fazer um comentário particular sobre o Setor Secundário. Neste, chama atenção a categoria 3-Indústria de transformação e 6-Construção, quejuntos empregam mais de 22\% da mão de obra da cidade. Sendo o setor secundário mais intensivo em capital, sua importância deve ser observada em termos de políticas públicas.

O início das análises será feito a partir dos geradores de empregos em razão da importância que este indicador tem para qualquer administrador público, procurando dar respostas sobre a capacidade que cada setor possui para gerar novos empregos após um estímulo na demanda final. Posto isto, a tabela 4 relaciona a distribuição dos geradores de empregos pelos 19 setores econômicos. 
É pertinente esclarecer que o gerador de emprego determina quantos empregos diretos são gerados no setor mais os indiretos em todos demais setores a cada unidade monetária produzida para a demanda final. Em outras palavras, faz-se uma estimativa de quantos novos empregos serão gerados após um aumento na demanda final da ordem de $\mathrm{R} \$ 1$ milhão de reais. Observando os resultados da tabela 4 é possível perceber em 2013 os setores que mais gerariam empregos na cidade de Londrina: 17-Saúde, 16-Educação, 18-Artes, cultura, esporte e recreação, 19-Outras atividades de serviços; e 14-Atividades administrativas e serviços complementares; isso para ficar apenas nos cinco primeiros.

Embora o setor 18-Artes, cultura, esporte e recreação apresente alto gerador de emprego, em termos relativos não emprega nem $1 \%$ da mão de obra de Londrina. Por isso éimportante ponderar o tamanho de cada setor dentro da economia, isto reflete o verdadeiro impacto em termos de criação de empregos.

Tabela 1- Geradores de emprego dos 19 setores do município de Londrina- 2013

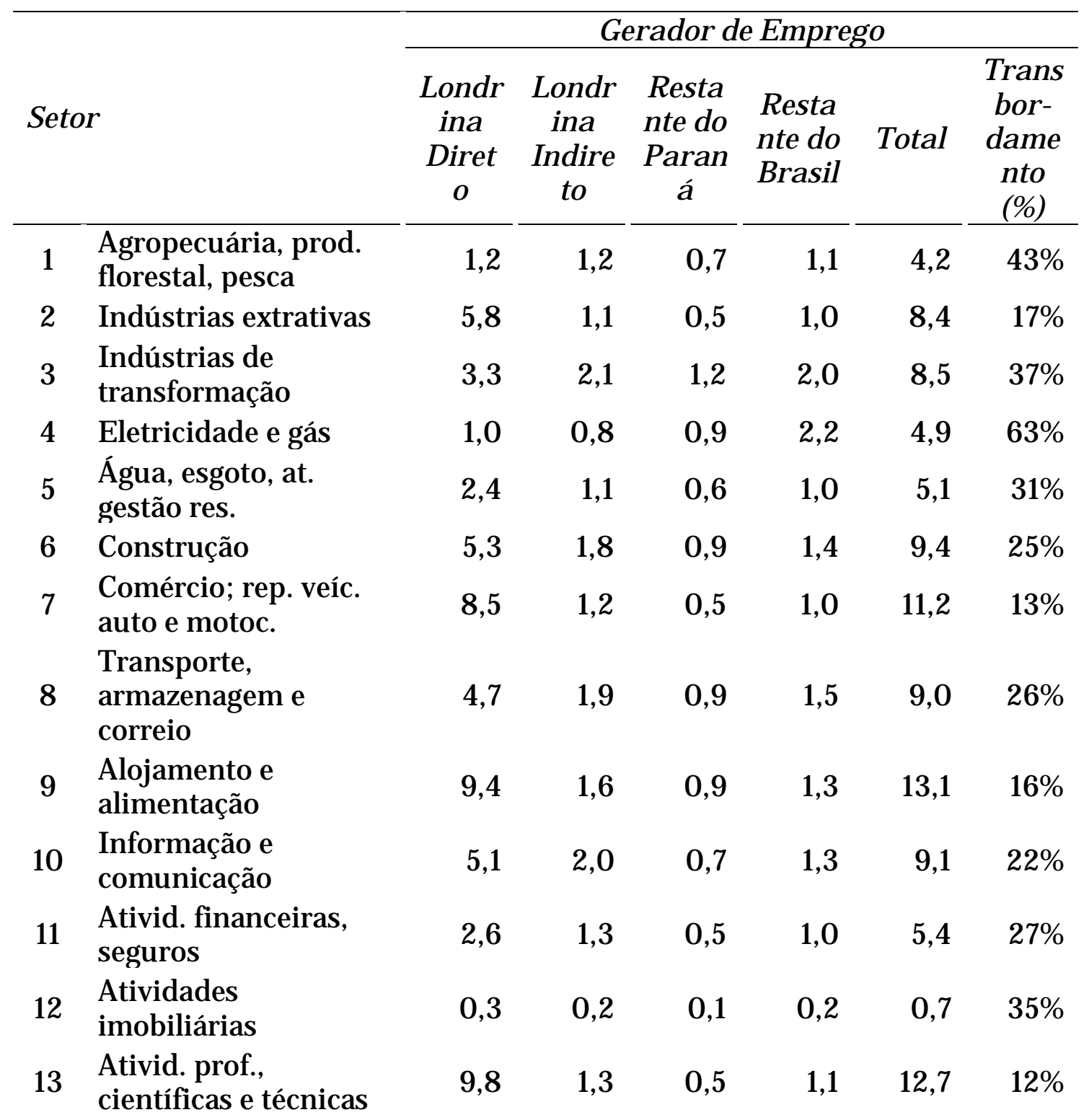




\begin{tabular}{|c|c|c|c|c|c|c|c|}
\hline 14 & $\begin{array}{l}\text { Atividades adm. e } \\
\text { serviços compl. }\end{array}$ & 10,4 & 0,9 & 0,4 & 0,8 & 12,6 & $10 \%$ \\
\hline 15 & $\begin{array}{l}\text { Adm. pública, defesa } \\
\text { e seg. social }\end{array}$ & 8,9 & 1,0 & 0,4 & 0,8 & 11,1 & $10 \%$ \\
\hline 16 & Educação & 14,8 & 1,0 & 0,4 & 0,7 & 16,8 & $6 \%$ \\
\hline 17 & $\begin{array}{l}\text { Saúde humana e } \\
\text { serviços sociais }\end{array}$ & 24,2 & 1,6 & 0,6 & 1,2 & 27,6 & $7 \%$ \\
\hline 18 & $\begin{array}{l}\text { Artes, cultura, } \\
\text { esporte e recreação }\end{array}$ & 13,8 & 1,2 & 0,5 & 1,1 & 16,6 & \\
\hline 19 & $\begin{array}{l}\text { Outras atividades de } \\
\text { serviços }\end{array}$ & 12,0 & 1,9 & 0,8 & 1,3 & 16,0 & $13 \%$ \\
\hline
\end{tabular}

Fonte: Elaborado pelo autor.

Evoluindo na avaliação dos resultados, os multiplicadores da tabela 5 mostram quantos empregos diretos e indiretos são gerados em Londrina, no Paraná e no restante do Brasil para cada emprego gerado no mesmo setor de Londrina. Tomando como exemplo o maior multiplicador da tabela 5, 1-Agropecuária; este número determina que para cada 1 emprego gerado na agropecuária de Londrina, outros 1,97 (direto e indireto) serão gerados em Londrina, mais 0,6 no restante do estado do Paraná, mais 0,87 no restante do Brasil, totalizando 3,45 empregos gerados apenas na agropecuária. Depois da agropecuária os maiores multiplicadores de emprego em Londrina são: 4-Eletrecidade e gás $(1,81)$; 12 Atividades imobiliárias (1,75); 3-Indústrias de transformação (1,62); e 11 Atividades financeiras $(1,50)$.

Tabela 2 - Multiplicadores de emprego dos 19 setores do município de Londrina - 2013

\begin{tabular}{|c|c|c|c|c|c|}
\hline \multirow{2}{*}{\multicolumn{2}{|c|}{ Setor }} & \multicolumn{4}{|c|}{ Multiplicador de Emprego } \\
\hline & & \multirow{2}{*}{$\begin{array}{r}\text { Londrina } \\
1,97\end{array}$} & \multirow{2}{*}{$\begin{array}{r}\text { Paraná } \\
0,60\end{array}$} & \multirow{2}{*}{$\begin{array}{r}\begin{array}{l}\text { Restante } \\
\text { do Brasil }\end{array} \\
0,87\end{array}$} & \multirow{2}{*}{$\begin{array}{r}\text { Total } \\
3,45\end{array}$} \\
\hline 1 & $\begin{array}{l}\text { Agropecuária, prod. } \\
\text { florestal, pesca }\end{array}$ & & & & \\
\hline 2 & Indústrias extrativas & 1,19 & 0,08 & 0,17 & 1,44 \\
\hline 3 & $\begin{array}{l}\text { Indústrias de } \\
\text { transformação }\end{array}$ & 1,62 & 0,35 & 0,59 & 2,57 \\
\hline 4 & Eletricidade e gás & 1,81 & 0,91 & 2,14 & 4,86 \\
\hline 5 & $\begin{array}{l}\text { Água, esgoto, at. gestão } \\
\text { res. }\end{array}$ & 1,44 & 0,23 & 0,42 & 2,09 \\
\hline 6 & Construção & 1,33 & 0,18 & 0,27 & 1,78 \\
\hline 7 & $\begin{array}{l}\text { Comércio; rep. veíc. } \\
\text { auto e motoc. }\end{array}$ & 1,14 & 0,06 & 0,12 & 1,32 \\
\hline 8 & $\begin{array}{l}\text { Transporte, } \\
\text { armazenagem e correio }\end{array}$ & 1,40 & 0,20 & 0,31 & 1,90 \\
\hline
\end{tabular}




\begin{tabular}{|c|c|c|c|c|c|}
\hline 9 & $\begin{array}{l}\text { Alojamento e } \\
\text { alimentação }\end{array}$ & 1,16 & 0,09 & 0,13 & 1,39 \\
\hline $\begin{array}{l}1 \\
0\end{array}$ & $\begin{array}{l}\text { Informação e } \\
\text { comunicação }\end{array}$ & 1,39 & 0,13 & 0,26 & 1,79 \\
\hline 11 & $\begin{array}{l}\text { Ativid. financeiras, } \\
\text { seguros }\end{array}$ & 1,50 & 0,17 & 0,37 & 2,04 \\
\hline $\begin{array}{l}1 \\
2\end{array}$ & Atividades imobiliárias & 1,75 & 0,33 & 0,61 & 2,68 \\
\hline $\begin{array}{l}1 \\
3\end{array}$ & $\begin{array}{l}\text { Ativid. prof., científicas } \\
\text { e técnicas }\end{array}$ & 1,14 & 0,05 & 0,11 & 1,30 \\
\hline $\begin{array}{l}1 \\
4\end{array}$ & $\begin{array}{l}\text { Atividades adm. e } \\
\text { serviços compl. }\end{array}$ & 1,09 & 0,04 & 0,08 & 1,21 \\
\hline $\begin{array}{l}1 \\
5\end{array}$ & $\begin{array}{l}\text { Adm. pública, defesa e } \\
\text { seg. social }\end{array}$ & 1,11 & 0,04 & 0,08 & 1,24 \\
\hline $\begin{array}{l}1 \\
6\end{array}$ & Educação & 1,06 & 0,02 & 0,05 & 1,13 \\
\hline $\begin{array}{l}1 \\
7\end{array}$ & $\begin{array}{l}\text { Saúde humana e } \\
\text { serviços sociais }\end{array}$ & 1,07 & 0,03 & 0,05 & 1,14 \\
\hline $\begin{array}{l}1 \\
8\end{array}$ & $\begin{array}{l}\text { Artes, cultura, esporte } \\
\text { e recreação }\end{array}$ & 1,09 & 0,04 & 0,08 & 1,20 \\
\hline $\begin{array}{l}1 \\
9\end{array}$ & $\begin{array}{l}\text { Outras atividades de } \\
\text { serviços }\end{array}$ & 1,16 & 0,07 & 0,11 & 1,33 \\
\hline
\end{tabular}

Fonte: Elaborado pelo autor.

Passando agora à análise dos geradores e multiplicadores de rendimento, tornase oportuno comentar que geradores sempre dizem respeito a resultados derivados de variações da ordem de $\mathrm{R} \$ 1$ milhão de reais na demanda final, que impactam neste caso, nos salários. Destemodo, e usando mais uma vez o exemplo da agropecuária, o gerador de rendimento simula quantos mil reais aumentarão em termos de massa salarial (salários dos trabalhadores) a cada aumento na demanda final da agropecuária em $\mathrm{R} \$ 1$ milhão de reais.

Pela análise dos resultados da tabela 6 é possível constatar que o 16-Educação é líder em geração de rendimento, representando que para cada $\mathrm{R} \$ 1$ milhão de aumento na demanda final no setor educacional, resultará num aumento da massa salarial em 0,668 milhões para seus trabalhadores. O resultado é condizente com as expectativas de que trabalhadores qualificados são remunerados melhor. Dois outros pontos podem ser extraídos daí, primeiramente que este segmento gera poucos rendimentos indiretos devido a sua característica de intensidade em mão de obra, ou seja, é um setor que utiliza menos insumos em seu processo produtivo relativamente à indústria de transformação ou agricultura. Em segundo lugar, o efeito transbordamento do gerador de rendimento da educação é o mais baixo entre todos os setores pesquisados. Isto quer dizer que o volume de recursos gerados neste setor circula na própria cidade. 
Seguindo na análise dos geradores, os próximos da tabela são: 17-Saúde; 15Administração pública; 13-Atividades profissionais científicas e técnicas; e 18Artes, cultura, esporte e recreação.

Tabela 3 - Geradores de rendimento dos 19 setores do município de Londrina-Pr $-2013$

\begin{tabular}{|c|c|c|c|c|c|c|c|}
\hline \multirow{2}{*}{\multicolumn{2}{|c|}{ Seto }} & \multicolumn{6}{|c|}{ Gerador de Rendimento } \\
\hline & & \multirow{3}{*}{$\begin{array}{c}\begin{array}{c}\text { Londr } \\
\text { ina }\end{array} \\
\begin{array}{c}\text { Diret } \\
\text { o }\end{array} \\
38\end{array}$} & \multirow{3}{*}{$\begin{array}{l}\begin{array}{c}\text { Londr } \\
\text { ina } \\
\text { Indire } \\
\text { to }\end{array} \\
27 \\
27\end{array}$} & \multirow{3}{*}{$\begin{array}{l}\begin{array}{c}\text { Indire } \\
\text { to } \\
\text { Paran } \\
\text { á }\end{array} \\
18\end{array}$} & \multirow{3}{*}{$\begin{array}{r}\begin{array}{r}\text { Indiret } \\
\text { o } \\
\text { Resto } \\
\text { do } \\
\text { Brasil }\end{array} \\
29\end{array}$} & \multirow{3}{*}{$\begin{array}{r}\text { Total } \\
111\end{array}$} & \multirow{3}{*}{ 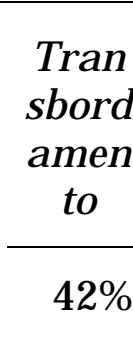 } \\
\hline & Agropecuária, prod. & & & & & & \\
\hline 1 & florestal, pesca & & & & & & \\
\hline 2 & Indústrias extrativas & 151 & 25 & 12 & 27 & 215 & $18 \%$ \\
\hline 3 & $\begin{array}{l}\text { Indústrias de } \\
\text { transformação }\end{array}$ & 70 & 46 & 27 & 54 & 198 & $41 \%$ \\
\hline 4 & Eletricidade e gás & 117 & 20 & 39 & 77 & 253 & $46 \%$ \\
\hline 5 & $\begin{array}{l}\text { Água, esgoto, at. gestão } \\
\text { res. }\end{array}$ & 47 & 23 & 15 & 29 & 115 & $38 \%$ \\
\hline 6 & Construção & 104 & 38 & 21 & 38 & 201 & $30 \%$ \\
\hline 7 & $\begin{array}{l}\text { Comércio; rep. veíc. } \\
\text { auto e motoc. }\end{array}$ & 168 & 27 & 13 & 27 & 236 & $17 \%$ \\
\hline 8 & $\begin{array}{l}\text { Transporte, } \\
\text { armazenagem e correio }\end{array}$ & 116 & 43 & 22 & 38 & 219 & $28 \%$ \\
\hline 9 & $\begin{array}{l}\text { Alojamen } \\
\text { alimentą }\end{array}$ & 140 & 34 & 20 & 33 & 228 & $24 \%$ \\
\hline $\begin{array}{l}1 \\
0\end{array}$ & $\begin{array}{l}\text { Informaça } \\
\text { comunica }\end{array}$ & 138 & 43 & 17 & 35 & 234 & $22 \%$ \\
\hline 11 & $\begin{array}{l}\text { Ativid. financeiras, } \\
\text { seguros }\end{array}$ & 144 & 35 & 13 & 28 & 220 & $19 \%$ \\
\hline $\begin{array}{l}1 \\
2\end{array}$ & Atividades imobiliárias & 5 & 6 & 3 & 5 & 19 & $40 \%$ \\
\hline $\begin{array}{l}1 \\
3\end{array}$ & $\begin{array}{l}\text { Ativid. prof., científicas } \\
\text { e técnicas }\end{array}$ & 264 & 33 & 13 & 31 & 341 & $13 \%$ \\
\hline $\begin{array}{l}1 \\
4\end{array}$ & $\begin{array}{l}\text { Atividades adm. e } \\
\text { serviços compl. }\end{array}$ & 181 & 21 & 11 & 22 & 236 & $14 \%$ \\
\hline & $\begin{array}{l}\text { Adm. pública, defesa e } \\
\text { seg. social }\end{array}$ & 404 & 24 & 11 & 21 & 459 & $7 \%$ \\
\hline $\begin{array}{l}1 \\
6\end{array}$ & Educação & 668 & 20 & 9 & 18 & 714 & $4 \%$ \\
\hline $\begin{array}{l}1 \\
7\end{array}$ & $\begin{array}{l}\text { Saúde humana e } \\
\text { serviços sociais }\end{array}$ & 446 & 33 & 14 & 30 & 523 & $8 \%$ \\
\hline $\begin{array}{l}1 \\
8\end{array}$ & $\begin{array}{l}\text { Artes, cultura, esporte } \\
\text { e recreação }\end{array}$ & 239 & 28 & 14 & 30 & 311 & $14 \%$ \\
\hline 1 & Outras atividades de & 208 & 39 & 18 & 34 & 299 & $18 \%$ \\
\hline
\end{tabular}


9 serviços

Fonte: Elaborado pelo autor.

Em razão da importância que os salários têm para a economia, é pertinente ilustrar também o efeito transbordamento, de modo a entender o quanto estes novos montantes salarias propulsionam a economia local ou servirão de estímulos a outas localidades. Neste sentido um gráfico pode contribuir bastante com a visualização dos resultados. Através da figura 1 é possível verificar que os setores primários, 1-Agricultura (42\%) e secundários, 4-Eletricidade e gás (46\%); 3-Indústria de transformação (41\%) ocupam a liderança do transbordamento, corroborando com a afirmação de que tais setores dependem mais de insumos provenientes de fora da região, o que estimula a geração de negócios em outras localidades. Daí também que o encadeamento produtivo local favorece o efeito multiplicador tão falado em economia.

Gráfico 1- Transbordamento do gerador de rendimento de Londrina-Pr

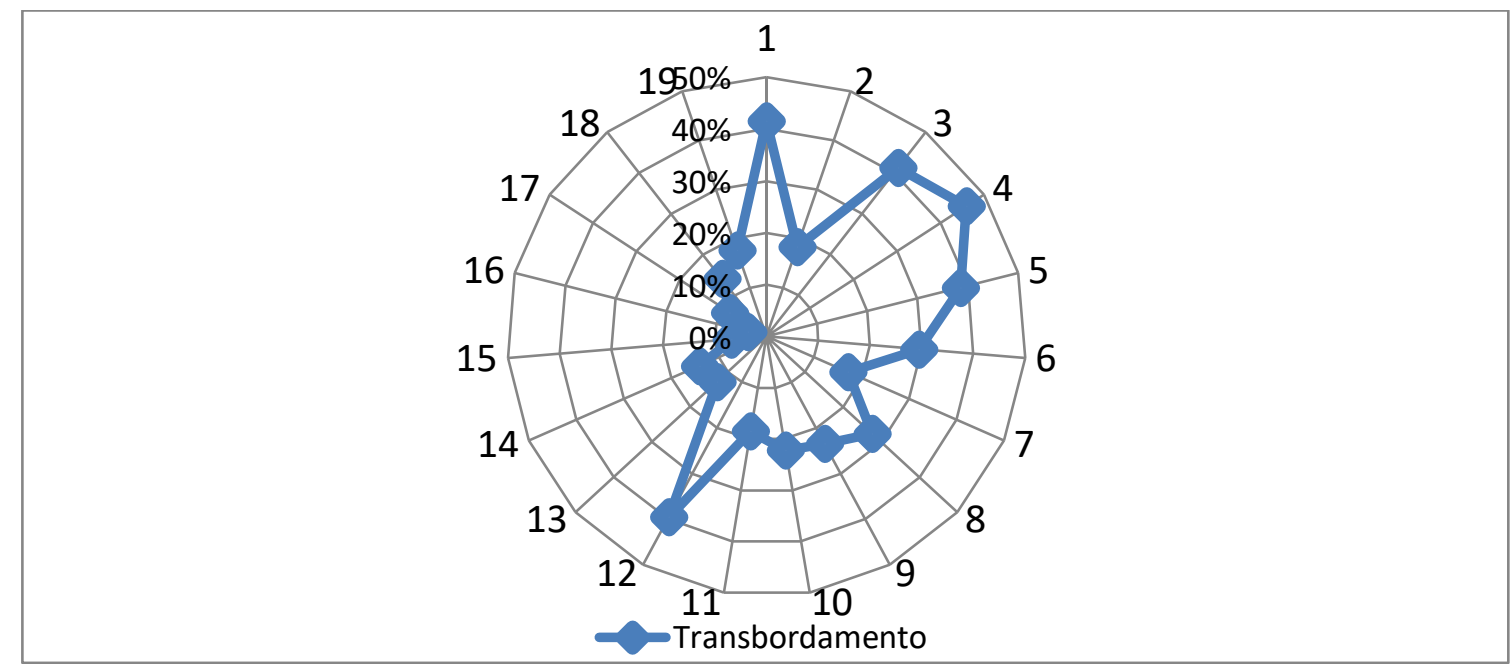

Fonte: Elaborado pelo autor.

Fechando as análises dos rendimentos pelo multiplicador e apresentando seus resultados na tabela 7 que determina quanto a massa salarial cresce a cada aumento de R\$ 1 milhão na demanda final, como líderes em geração de rendimento aparecem: 12-Atividades imobiliárias; 1-Agropecuária; 3-Indústria de transformação; 5-Água, esgoto; e 8-Transporte.

Tabela 4 - Multiplicadores de rendimentos dos 19 setores do município de Londrina-Pr - 2013

\begin{tabular}{|c|c|c|c|c|}
\hline \multirow[b]{2}{*}{ Setor } & \multicolumn{4}{|c|}{ Multiplicador de Rendimento } \\
\hline & Londrina & Paraná & $\begin{array}{l}\text { Restante } \\
\text { do Brasil }\end{array}$ & Total \\
\hline $\begin{array}{l}\text { Agropecuária, prod. } \\
\text { florestal, pesca }\end{array}$ & 1,69 & 0,46 & 0,74 & 2,89 \\
\hline
\end{tabular}




\begin{tabular}{|c|c|c|c|c|c|}
\hline 2 & Indústrias extrativas & 1,17 & 0,08 & 0,18 & 1,43 \\
\hline 3 & $\begin{array}{l}\text { Indústrias de } \\
\text { transformação }\end{array}$ & 1,66 & 0,39 & 0,77 & 2,82 \\
\hline 4 & Eletricidade e gás & 1,17 & 0,33 & 0,66 & 2,16 \\
\hline 5 & $\begin{array}{l}\text { Água, esgoto, at. gestão } \\
\text { res. }\end{array}$ & 1,50 & 0,32 & 0,62 & 2,43 \\
\hline 6 & Construção & 1,37 & 0,21 & 0,36 & 1,94 \\
\hline 7 & $\begin{array}{l}\text { Comércio; rep. veíc. } \\
\text { auto e motoc. }\end{array}$ & 1,16 & 0,08 & 0,16 & 1,40 \\
\hline 8 & $\begin{array}{l}\text { Transporte, } \\
\text { armazenagem e correio }\end{array}$ & 1,37 & 0,19 & 0,33 & 1,89 \\
\hline 9 & $\begin{array}{l}\text { Alojamento e } \\
\text { alimentação }\end{array}$ & 1,24 & 0,14 & 0,24 & 1,62 \\
\hline $\begin{array}{l}1 \\
0\end{array}$ & $\begin{array}{l}\text { Informação e } \\
\text { comunicação }\end{array}$ & 1,31 & 0,12 & 0,25 & 1,69 \\
\hline 11 & $\begin{array}{l}\text { Ativid. financeiras, } \\
\text { seguros }\end{array}$ & 1,24 & 0,09 & 0,19 & 1,53 \\
\hline $\begin{array}{l}1 \\
2\end{array}$ & Atividades imobiliárias & 2,14 & 0,48 & 0,93 & 3,54 \\
\hline $\begin{array}{l}1 \\
3\end{array}$ & $\begin{array}{l}\text { Ativid. prof., científicas } \\
\text { e técnicas }\end{array}$ & 1,13 & 0,05 & 0,12 & 1,29 \\
\hline $\begin{array}{l}1 \\
4\end{array}$ & $\begin{array}{l}\text { Atividades adm. e } \\
\text { serviços compl. }\end{array}$ & 1,12 & 0,06 & 0,12 & 1,30 \\
\hline $\begin{array}{l}1 \\
5\end{array}$ & $\begin{array}{l}\text { Adm. pública, defesa e } \\
\text { seg. social }\end{array}$ & 1,06 & 0,03 & 0,05 & 1,14 \\
\hline $\begin{array}{l}1 \\
6\end{array}$ & Educação & 1,03 & 0,01 & 0,03 & 1,07 \\
\hline $\begin{array}{l}1 \\
7\end{array}$ & $\begin{array}{l}\text { Saúde humana e } \\
\text { serviços sociais }\end{array}$ & 1,07 & 0,03 & 0,07 & 1,17 \\
\hline 1 & $\begin{array}{l}\text { Artes, cultura, esporte } \\
\text { e recreação }\end{array}$ & 1,12 & 0,06 & 0,13 & 1,30 \\
\hline $\begin{array}{l}1 \\
9\end{array}$ & $\begin{array}{l}\text { Outras atividades de } \\
\text { serviços }\end{array}$ & 1,19 & 0,09 & 0,16 & 1,44 \\
\hline
\end{tabular}

Fonte: Elaborado pelo autor.

SÁ (2014) aponta que a matriz insumo-produto possibilita o cálculo dos coeficientes técnicos, ou seja, o quanto uma determinada atividade precisa consumir de produtos das outras atividades para executar a sua produção. Ao mesmo tempo, segundo o mesmo autor, os multiplicadores de Leontief mostram o quanto o aumento da demanda de uma atividade afeta a produção das outras atividades após levarem-se em conta os efeitos indiretos. De maneira mais precisa, tem-se que o multiplicador de produção estima quanto é gerado de produção em cada setor direta e indiretamente nos outros setores a cada variação de unidade monetária na demanda final do setor. A figura 2 mostra que os setores 
líderes são: 3-Indústria de transformação (1,47); 8-Transporte, armazenagem e correio (1,38); 6-Construção (1,37); 9-Alojamento e alimentação (1,34); e 19Outras atividades de serviços $(1,30)$.

Gráfico 2 - Multiplicador de produção de Londrina-Pr - 2013

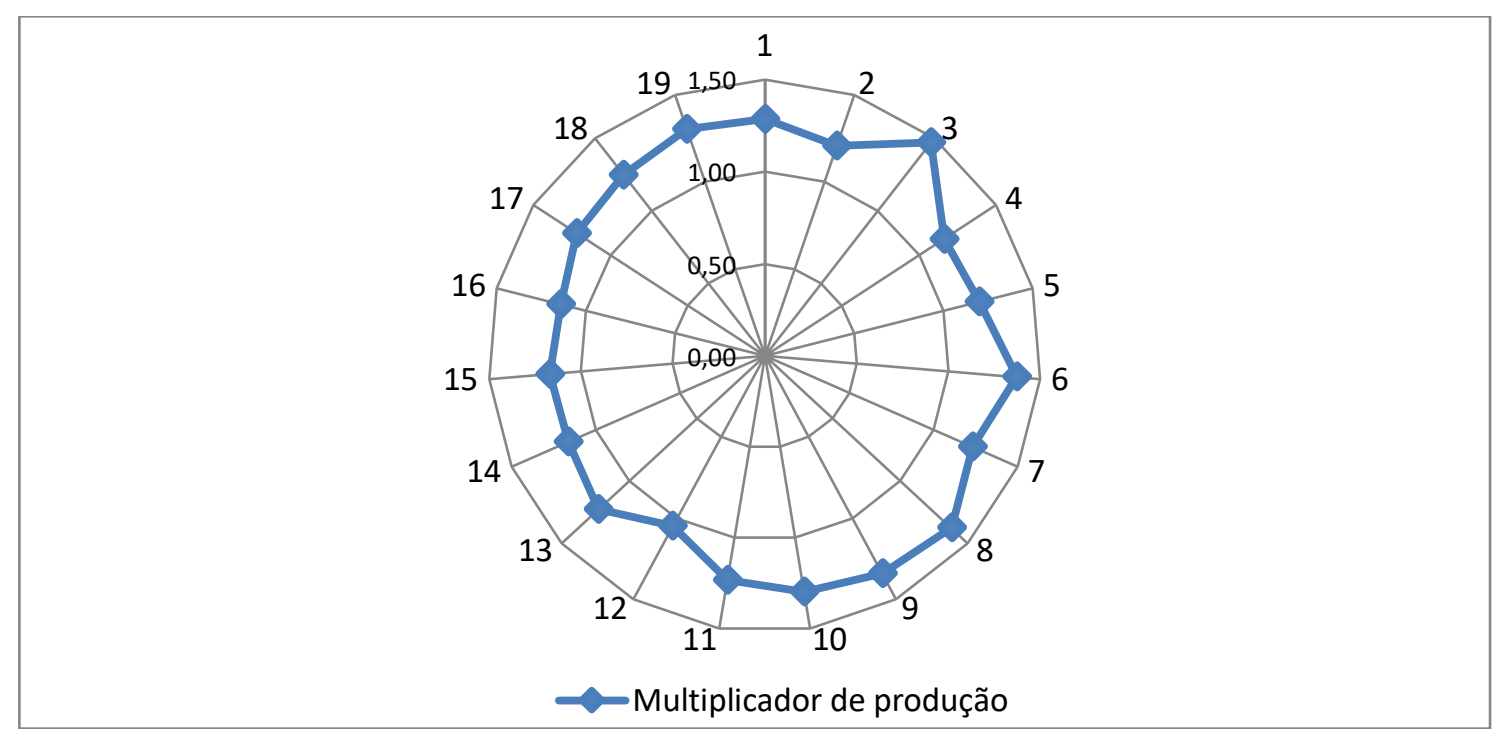

Fonte: Elaborado pelo autor.

Procurando identificar o encadeamento dos setores produtivos em Londrina, partindo do modelo de Leontief e utilizando Rasmussen (1956) e Hirschman (1958), determinam-se tanto os índices de ligações para trás, que especificam quanto tal setor demandaria dos outros, quanto os de ligações para frente, que informa a quantidade de produtos demandados de outros setores da economia pelo setor em questão, de tal modo que os valores maiores que 1 estão relacionados a setores acima da média, e, portanto, setores-chave para o crescimento da economia. Em Londrina, setores acima da média estão relacionados na tabela 8 e são: 3-Indústria de transformação (1,18); 8-Transporte $(1,10)$; e 10-Informação e comunicação $(1,04)$.

Numa análise mais minuciosa nota-se que os setores que mais demandam insumos para seu processo produtivo são: 3-Indústria de transformação $(1,18)$; 6-Construção $(1,10)$; 8-Transporte, $(1,10)$; 9-Alojamento e alimentação $(1,08)$ e; 10-Informação e comunicação $(1,04)$. Por outro lado, os setores que mais vendem insumos para outros setores são: 3-Indústria de Alimentos (1,99); 7-Comércio $(1,28)$; 8-Transporte (1,21); 14-Atividades administrativas (1,18); e 11-Atividades financeiras $(1,09)$.

Tabela 5 - Índices de ligações intersetoriais de Rasmussen-Hirschman para o município de Londrina-Pr - 2013 Índices de Ligaçõe 


\begin{tabular}{|c|c|c|c|}
\hline & & Para trás & Para frente \\
\hline 1 & $\begin{array}{l}\text { Agropecuária, prod. } \\
\text { florestal, pesca }\end{array}$ & 1,03 & 0,97 \\
\hline 2 & Indústrias extrativas & 0,97 & 0,80 \\
\hline 3 & $\begin{array}{l}\text { Indústrias de } \\
\text { transformação }\end{array}$ & 1,18 & 1,99 \\
\hline 4 & Eletricidade e gás & 0,93 & 0,81 \\
\hline 5 & $\begin{array}{l}\text { Água, esgoto, at. gestão } \\
\text { res. }\end{array}$ & 0,96 & 0,81 \\
\hline 6 & Construção & 1,10 & 0,95 \\
\hline 7 & $\begin{array}{l}\text { Comércio; rep. veíc. } \\
\text { auto e motoc. }\end{array}$ & 0,99 & 1,28 \\
\hline 8 & $\begin{array}{l}\text { Transporte, } \\
\text { armazenagem e correio }\end{array}$ & 1,10 & 1,21 \\
\hline 9 & $\begin{array}{l}\text { Alojamento e } \\
\text { alimentação }\end{array}$ & 1,08 & 0,89 \\
\hline $\begin{array}{l}1 \\
0\end{array}$ & $\begin{array}{l}\text { Informação e } \\
\text { comunicação }\end{array}$ & 1,04 & 1,02 \\
\hline 11 & $\begin{array}{l}\text { Ativid. financeiras, } \\
\text { seguros }\end{array}$ & 0,99 & 1,09 \\
\hline $\begin{array}{l}1 \\
2\end{array}$ & Atividades imobiliárias & 0,84 & 0,95 \\
\hline $\begin{array}{l}1 \\
3\end{array}$ & $\begin{array}{l}\text { Ativid. prof., científicas } \\
\text { e técnicas }\end{array}$ & 0,98 & 0,94 \\
\hline $\begin{array}{l}1 \\
4\end{array}$ & $\begin{array}{l}\text { Atividades adm. e } \\
\text { serviços compl. }\end{array}$ & 0,93 & 1,18 \\
\hline $\begin{array}{l}1 \\
5\end{array}$ & $\begin{array}{l}\text { Adm. pública, defesa e } \\
\text { seg. social }\end{array}$ & 0,94 & 0,82 \\
\hline $\begin{array}{l}1 \\
6\end{array}$ & Educação & 0,92 & 0,81 \\
\hline $\begin{array}{l}1 \\
7\end{array}$ & $\begin{array}{l}\text { Saúde humana e } \\
\text { serviços sociais }\end{array}$ & 0,98 & 0,81 \\
\hline $\begin{array}{l}1 \\
8\end{array}$ & $\begin{array}{l}\text { Artes, cultura, esporte } \\
\text { e recreação }\end{array}$ & 1,00 & 0,82 \\
\hline $\begin{array}{l}1 \\
9 \\
\end{array}$ & $\begin{array}{l}\text { Outras atividades de } \\
\text { serviços }\end{array}$ & 1,04 & 0,84 \\
\hline
\end{tabular}

Fonte: Elaborado pelo autor.

Sobre as análises de integração econômica é apropriado citar o estudo de Moretto et al (2014) comparando as estruturas inter-regional e intersetorial da economia paranaense nas relações de compra e venda com as demais regiões do sistema. Utilizando as técnicas de Rasmussen-Hirschman os autores concluíram que as regiões polarizadas por Curitiba e Londrina são melhores articuladas que as 
demais em termos de estrutura industrial, ao mesmo tempo que a região polarizada de Londrina, Ponta Grossa e Cascavel aumentaram a integração com a região polarizada de Curitiba.

Gráfico 3 - Índices de ligações intersetoriais de Rasmussen-Hirschman para o município de Londrina-Pr- 2013

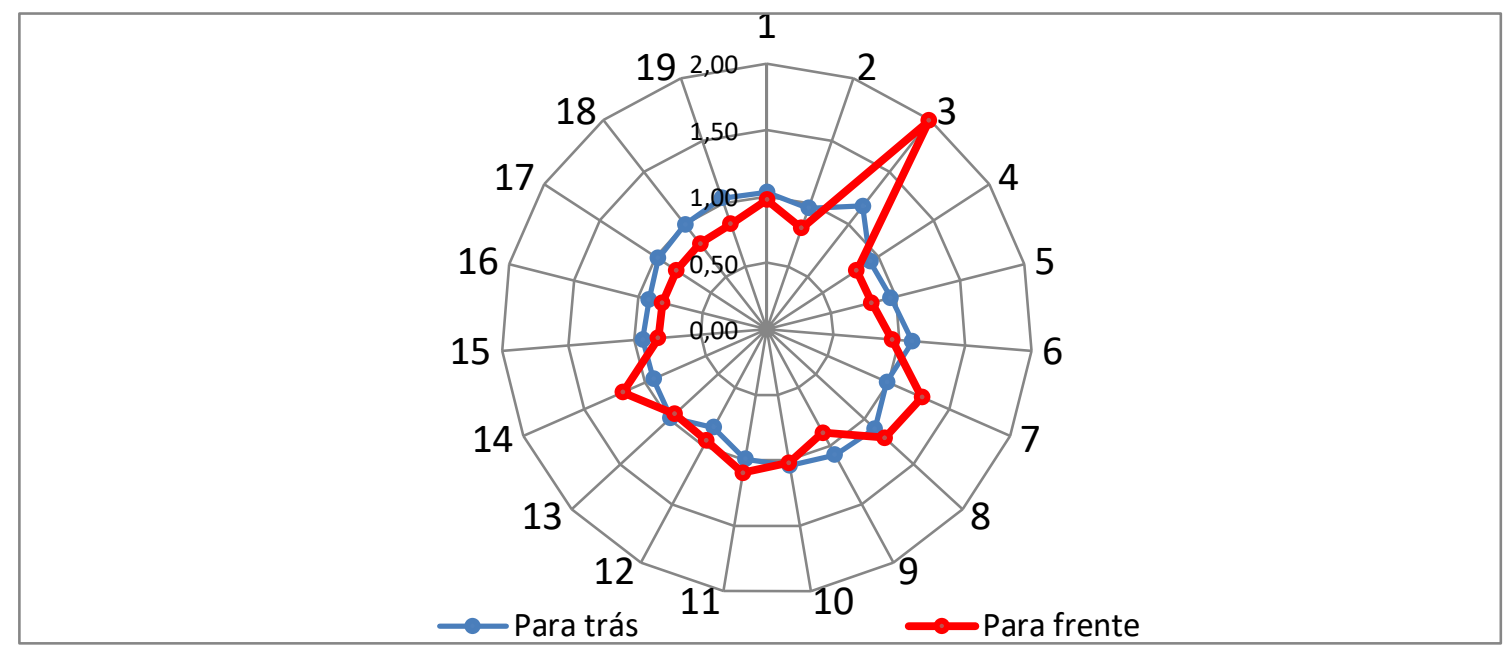

Fonte: Elaborado pelo autor.

Finalizando a análise da estrutura econômica de Londrina pelos resultados do campo de influência, de acordo com Anefalos e Guilhoto (2003), o campo de influência mostra quais os coeficientes técnicos (estrutura de produção) que, se alterados, mais transformam a matriz inversa e, portanto, mais modificam os encadeamentos sucessivos causados por uma variação da demanda. Entre os setores 1 a 19 que se relacionam em termos de compra e vendas de insumos, o sistema inter-regional de Londrina destaca como comprador os setores 3Indústria de transformação; 6-Construção; 8-Transporte; 10-Informação e comunicação; e 11-Atividades financeiras.

Em relação aos setores vendedores, o campo de influência mostra seis principais: 1-Agricultura; 3-Indústria de transformação; 6-Construção; 8-Transporte; 10Informação e comunicação; e 11-Atividades financeiras.

Dos setores compradores e vendedores, interessante notar que quatro são iguais, ou seja, possuem forte potencial de compra e venda ao mesmo tempo. O único setor dentro dos cinco maiores que não apresenta esta característica é o 1Agricultura que embora apresente uma participação significativa em compra dos demais setores, vende em quantidades limitadas aos demais participantes da economia. 
Gráfico 4 - Setores com maior campo de influência do Sistema de Londrina-Pr 2013

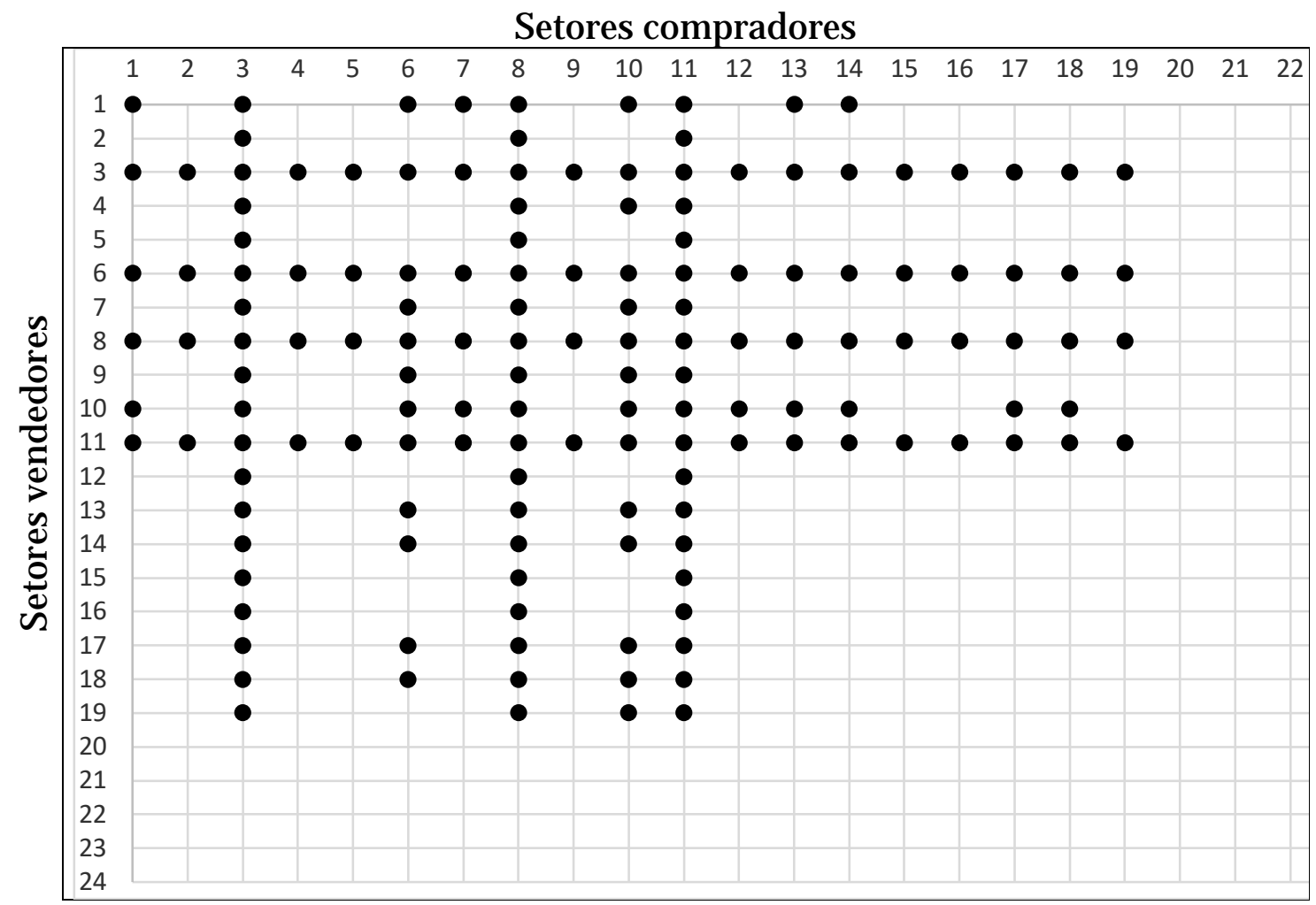

Fonte: Elaborado pelo autor.

Os resultados dos indicadores apresentados buscou traçar um panorama estrutural da economia de Londrina. As características embasadas no senso comum de quea cidadeé prestadora de serviços é correta, entretanto o diferencial desta pesquisa é trazer conhecimento sobre as potencialidades da cidade através de uma análise científica e instrumentada na MIP, esmiuçando os multiplicadores, geradores eíndices de ligações intersetoriais, além de tratar com o rigor técnico o campo de influência dos setores econômicos local.

\section{Considerações Finais}

É realidade latente a escassez de recursos públicos que os governos enfrentam em face aos problemas econômicos e sociais de nossa sociedade. Com demandas crescentes e recursos limitados se torna extremamente importante que os instrumentos de planejamento sejam utilizados com racionalidade, pautando as decisões estratégicas e maximizando a utilidade no uso dos recursos. Neste contexto, as matrizes insumo-produto se apresentam como elemento importante de planejamento econômico e tomada de decisão. 
A fim de contribuir para o conhecimento das oportunidades e fragilidades econômicas de Londrina, os resultados deste trabalho se mostraram satisfatórios e apontaram que a matriz insumo-produto foi estimada de maneira adequada, aproximando-se inclusive, das observações empíricas já feitas sobre a realidade local.

Os índices mostraram que setores como educação e saúde apresentam maiores geradores de empregos. Importante destacar o caso da educação em especial, pois o setor possui a terceira maior média salarial do município, apontando capacidade para gerar elevado número de empregos ao mesmo tempo em que oferta salários acima da média da cidade.

O multiplicador de produção teve a liderança da indústria de transformação. Assim, é importante destacar que a cidade tem um trabalho amplo a desenvolver no sentido de fortalecer a indústria local devido ao grande potencial de agregação de valor e geração de riqueza.

Como setor-chave para a geração de rendimento formal, além da educação e saúde, aparece a administração pública, segmento que ainda tem grande peso na economia do município, já que instituições como a prefeitura de Londrina, por exemplo, é a que mais emprega atualmente.

A indústria de transformação, o setor de transporte e o setor de comunicação apresentaram os maiores índices de ligação na cadeia produtiva. Estudos futuros poderão ampliar a desagregação dos setores, especialmente na indústria, para aprofundar as análises sobre suas potencialidades e especificidades.

\section{Referências}

BRENE, P.R.A.; SESSO FILHO, U.A.; DALLA COSTA, A.J .; RANGEL, R.R. (2011). Estimativa da matriz de insumo-produto do município de São Bento do Sul no Estado de Santa Catarina. Revista Brasileira deGestão e Desenvolvimento Regional, v. 7, pp. 250-269.

BRENE, P.R.A.; SESSO FILHO, U.A.; RODRIGUES, R.L.; DALLA COSTA, A.J . (2010). Matriz de insumo-produto de Arapongas/ PR: perspectivas de uma nova ferramenta para o desenvolvimento local. Revista Brasileira de Estudos Regionais e Urbanos, v. 4, pp. 9.

BRENE, P.R.A.; SESSO FILHO, U.A.; DALLA COSTA, A.J . (2014a). Análise da Viabilidade do Uso de Indicadores Provenientes de Matrizes Insumo-Produto Regionais Estimadas: apresentação e teste da proposta metodológica. Revista Paranaense de Desenvolvimento (Online), v. 35, pp. 155-180.

BRENE, P.R.A.; SESSO FILHO, U.A.; PORSSE, A.A.; DALLA COSTA, DALLA COSTA, A.J . (2014b). Sistema Inter-Regional do Município de Curitiba/ PR: Uma Análise Insumo-Produto em Três Esferas (Município - Estado - País). Revista de Economia (Curitiba), v. 40, pp. 112-145.

CARAVIERI, A.M.M.; BRENE, P.R.A.; SESSO FILHO, U.A.; CAMPOS, A.C.; RODRIGUES, R.L. (2014). APL madeireiro e mobiliário de São Bento do Sul e de Arapongas: uma análise comparativa utilizando o índice Rasmussen-Hirschman. Informe GEPEC (Online), v. 18, pp. 101-118. 
FERNANDES, E.S.M.; BRENE, P.R.A.; CARAVIERI, A.M.M.; SESSO FILHO, U.A. (2014). Um Estudo dos APL's de São Bento do Sul (SC) e Arapongas (PR) com a contribuição do Índice de Interação Sinergética. Revista Espacios, v. 35, pp. 4-4

GUILHOTO, J.J.M., M. SONIS, E G.J.D. HEWINGS. (1996). Linkages and Multipliers in a Multiregional Framework: Integrations of Alternative Approaches. Discussion Paper 96-T-8. Regional Economics Applications Laboratory, University of Illinois.

GUILHOTO, J.J.M., SESSO FILHO, U.A. (2005a). Estimação da matriz de insumo-produto a partir de dados preliminares das contas nacionais. Economia Aplicada, v.9, n.2, pp.277-299, abr/jun/ 2005.

GUILHOTO, J.J.M., SESSO FILHO, U.A. (2005b). Estrutura produtiva da Amazônia: uma análise de insumo-produto. Belém: Banco da Amazônia, 320p.

IBGE. INSTITUTO BRASILEIRO DE GEOGRAFIA E ESTATÍSTICA. Contas Regionais. http:www.ibge.gov.br acesso em 20/06/2016.

ISARD, W. (1951). Inter-regional and Regional Input-Output Analysis: A Model of a Space-Economy. Review of Economics and Statistics, n.33, pp.319-328.

ISSA, A.A.; BRENE, P.R.A.; CARAVIERI, A.M.M.; SESSO FILHO, U.A. (2015). Um estudo dos APLs de São Bento do Sul (SC) e Arapongas (PR) a partir dos multiplicadores de produção, emprego e renda. Revista Capital Científico (UNICENTRO), v. 13, pp. 95-114.

LEONTIEF, W. (1986). Input-Output Economics. Segunda Edição. New York: Oxford University Press.

LEONTIEF, W. (1951). The Structure of the American Economy. Segunda Edição Ampliada. New York: Oxford University Press

MILLER, R.E. E BLAIR, P.D. (2009). Input-Output Analysis: Foundations and Extensions. Cambridge: Cambridge University Press.

MORETTO, A. C. (2000). Relações intersetoriais e inter-regionais na economia paranaense em 1995. Piracicaba, 2000. 161p. Tese (Doutorado) - Escola Superior de Agronomia Luiz de Queiroz, Universidade de São Paulo.

TAROCCO FILHO, J.; SESSO FILHO, U.A.; ESTEVES, E.G.Z.; KURESKI, R. (2014). Impacto econômico de curto prazo da Universidade Estadual de Londrina. Economia \& Região, v. 2, pp. 83-103. 